\title{
Evaluation of patients' satisfaction: A case study of the dental clinic of Obafemi Awolowo University Teaching Hospital Complex, Ile-Ife, Nigeria
}

\author{
Olaniregun, A.A. ${ }^{1}$, *Adeyemi, M.F. ${ }^{1}$, Oyetola, O.E. ${ }^{2}$, Ernest, M.A. ${ }^{1}$, Ehigie, I. ${ }^{1}$, \\ Onasanya, O.H. ${ }^{1}$
}

\begin{abstract}
Objective: Understanding patients' satisfaction after treatments is an important aspect of human medicine. Considering the paucity of information on dental patients' satisfaction after treatment or care in Nigeria thus, this study was to evaluate patients' satisfaction following treatments at the dental clinic of Obafemi Awolowo University Teaching Hospital, Ile-Ife, Osun State, Nigeria.
\end{abstract}

Methods: A total of 150 patients were recruited for the study by convenience sampling while a selfadministered questionnaire was used to gather patient's bio data, access to care, quality of care and general satisfaction.

Result: Majority of the patients $64.7 \%$ reported satisfactory, $31.3 \%$ reported very satisfactory whereas, only $4.0 \%$ of the patients reported unsatisfactory.

Conclusion: This study confirms that majority of participants had considerable level of satisfaction with the dental care received. However, more ultra-modern dental facilities should be provided to enhance safe and efficient dental care.

Keywords: Satisfaction, dissatisfaction, patients, dental, care

\author{
*Correspondence Author \\ DrAdeyemi, M.F. \\ Email: adeyemimoshood@yahoo.com
} ${ }^{1}$ Department of Surgery, University of Ilorin Teaching Hospital, Ilorin, Nigeria.
${ }^{2}$ Department of Preventive Dentistry, Faculty of Dentistry, College of Health Sciences, Obafemi Awolowo
University, Ile Ife, Nigeria. 


\title{
Évaluation de la satisfaction des patients: Étude de cas de la clinique dentaire du complexe hospitalier universitaire de Obafemi Awolowo, Ile-Ife, Nigéria
}

\author{
Olaniregun, A.A. ${ }^{1}$, *Adeyemi, M.F. ${ }^{1}$, Oyetola, O.E. ${ }^{2}$, Ernest, M.A. ${ }^{1}$, Ehigie, I. ${ }^{1}$, \\ Onasanya, O.H. ${ }^{1}$
}

\begin{abstract}
Resume
Objectif: Comprendre la satisfaction des patients après les traitements est un aspect important de la médecine humaine. Compte tenu de la pénurie d'informations sur la satisfaction des patients après un traitement ou des soins au Nigéria, cette étude devait donc évaluer la satisfaction des patients après des traitements à la clinique dentaire de l'hôpital universitaire d'Obafemi Awolowo, Ile-Ife, dans l'État d'Osun, au Nigéria.
\end{abstract}

Méthodes: Un total de 150 patients ont été recrutés pour l'étude par échantillonnage de commodité, tandis qu'un questionnaire auto-administré a été utilisé pour recueillir les données biologiques, l'accès aux soins, la qualité des soins et la satisfaction générale des patients.

Résultat: La majorité des patients $64,7 \%$ ont déclaré satisfaisant, $31,3 \%$ très satisfaisant, alors que seulement $4,0 \%$ des patients ont déclaré insatisfaisant.

Conclusion: cette étude confirme que la majorité des participants étaient très satisfaits des soins dentaires reçus. Cependant, des installations dentaires plus modernes devraient être mises en place pour améliorer la sécurité et l'efficacité des soins dentaires.

Mots-clés: satisfaction, insatisfaction, patients, soins dentaires, soins

\author{
*Correspondence Author \\ DrAdeyemi, M.F. \\ Email: adeyemimoshood@yahoo.com
}

${ }^{1}$ Department of Surgery, University of Ilorin Teaching Hospital, Ilorin, Nigeria.

${ }^{2}$ Department of Preventive Dentistry, Faculty of Dentistry, College of Health Sciences, Obafemi Awolowo University, Ile Ife, Nigeria.

Research Journal of Health Sciences subscribed to terms and conditions of Open Access publication. Articles are distributed under the terms of Creative Commons Licence (CC BY-NC-ND 4.0). (http://creativecommons.org/licences/by-nc-nd/4.0).

http://dx.doi.org/10.4314/rejhs.v7i2.6 


\section{INTRODUCTION}

Patient satisfaction is a cognitive evaluation of the service that is emotionally affected, and it is therefore an individual subjective perception about medical care or attention. Hence, if a patient is to be adequately served, then she/he must have a voice in the process of care (1). Several studies have reported multidimensional concept of patients' satisfaction following care however, the researches underscore the notion that since satisfaction is multidimensional, patients can be satisfied with some areas of care, but not with others (2-5). Patients require regular oral health examinations and dental treatments to lessen discomfort, improve dental appearance, and enhance occlusal functions. Accessibility and convenience are often the most relevant aspects for patients when selecting a dental health facility (1).

Various studies (6-7) have also reported different dimensions of patients' satisfaction. Poor communication between dental health practitioner and patient, low confidence in the dental care giver, and complaints about the quality and fees have been associated with poor compliance with dental recommendations, low utilization and/or the termination of treatment.

Newsome et al stated that as with health care in general, patient satisfaction has also been shown to influence compliance and in turn, treatment quality. Possible factors that may influence patient's decision include ease of access and transportation to the clinic, clinical facilities, medical equipment, and expenses, billing methods, recommendations from family and friends, and media advertisements (4).

If satisfaction influences compliance, and better compliance means healthier patients in the long term, then perhaps the most effective way to improve compliance for younger patients is to increase their general satisfaction with the dental practice.

Hence, the primary aim of this study was to assess the level of satisfaction of patients attending dental clinic of the Obafemi Awolowo University Teaching Hospital's complex (OAUTHC) for treatment.

\section{MATERIALS AND METHODS Patients and Study Design}

This study relied on information provided by patients attending the dental clinic of the Obafemi Awolowo University Teaching Hospital's complex (OAUTHC). Patients' consent was sought; parents gave consent for the minors before recruitment into the study.A total of one hundred and fifty (150) patients (aged 8 85 years) with no other co-morbidities apart from oral health challenges that attended the clinic as their first visit between the study periods that satisfied the inclusion criteria were selected. The study lasted for 6 months.

\section{Data Collection}

A self-administered structured questionnaire was used for collecting data in this study. Several statements were used to measure the research construct. Basically, the questionnaire evaluated the views and feelings of patients with respect to the level of satisfaction with dental care services at the OAUTHC dental clinic. There were 26 questions drafted for the purpose of the study. The questions focus on the following areas: patient's bio data, access to care, quality of care and general satisfaction. The questionnaire was divided into 4 sections with each section containing different questions relevant to the study. The first section comprised of different questions about patients bio data e.g. gender, age, marital status etc. The focus of the second section was on access to care. The third section entails detailed questions on the quality of care before, during and after treatment, and the last section was on general satisfaction. Questionnaires were completed after treatment at the various specialists' sections at the dental clinic; oral surgery, restorative, preventive/periodontology and child dental health clinics.

After the questionnaire had been administered and collected from the respondents, responses were checked for consistency and detection of error in order to make amendment where necessary. Out of a total of 200 questionnaires administered; 186 were retrieved and only 150 were deemed valid for analysis. Data retrieved was entered and analyzed using SPSS, version20. Frequency distribution tables were generated for age, gender, marital status, educational background, and occupation, level of patients' satisfaction while mean and standard deviation were also determined respectively. Differences with p-value of 0.05 or less were considered statistically significance. Responses gathered for each of the category of patients' satisfaction were grouped into very satisfactory, satisfactory and non-satisfactory accordingly.

\section{RESULTS}

Majority (68.0\%) of the respondents fall within11-30yrs age group while other age group 
$<10$ years, 31-50 years and $>71$ years accounts for $0.7 \%, 15.3 \%$ and $3.3 \%$ respectively. The mean age of the respondents was 31 years while the standard deviation of the age of the respondents is 15.81 . The ratio of male to female is $11: 9$ while that of single to married was $2: 1$. Educational background followed this pattern: $78 \%$ of the respondents had tertiary education, $17.3 \%$ had secondary education, $2.7 \%$ had primary education (2.7\%) and $2.0 \%$ had no education $(2.0 \%)$. The occupation of the respondents were as follows; Students $(61.3 \%)$, Professionals (24\%), Artisans (10.7\%) and Retirees (4\%) respectively.

The level of patients' satisfaction based on patients' opinions was presented in Table 2 . Majority of the respondents (89\%) agreed that the dental clinic was well located or accessible with male and female accounting for $44 \%$ and $56 \%$ respectively. Similarly, most of the respondents $(75 \%)$ agreed that the waiting area is comfortable with male and female accounting for $42 \%$ and $58 \%$ of the respondents respectively. Greater percentage $(71 \%)$ of the patients disagreed that they had delay seeing the dentists with male being $46 \%$ and female $54 \%$. Most of the respondents $(93 \%)$ agreed that enough personnel are available to give dental care with $45 \%$ male and $55 \%$ female. Furthermore, majority of the respondents $(92 \%)$ agreed that there are enough dental operatives with male and female accounting for $43 \%$ and $57 \%$ respectively. Also, more respondents (73\%) agreed that they were well attended to by the receptionist; male and female being $41 \%$ and $59 \%$ respectively. About $2 / 3^{\text {rd }}$ of the patients $(63 \%)$ agreed that they understood the cause of their complaints prior to treatment commencement with male and female accounting for $46 \%$ and $54 \%$ respectively. Almost all of the respondents (95\%) agreed that good infection control mechanism were observed in handling instruments with male and female accounting for $44 \%$ and $56 \%$ respectively. Also, most of the respondents (91\%) agreed that they were carried along during the treatment with male and female being $45 \%$ and 55\% respectively. Majority of the respondents (94\%) agreed that they were given postoperative instructions to follow. Likewise, 95\% agreed that they understood the instructions with male and female accounting for $45 \%$ and $55 \%$ respectively. Majority of the respondents $(76 \%)$ had appointment for review after the treatment with male and female being $48 \%$ and $52 \%$ respectively. Similarly, $86 \%$ of the respondents agreed that they complied with the instructions; male and female accounting for $43 \%$ and $57 \%$ respectively. Most of the respondents $(66 \%)$ agreed that there was improvement before their review appointment with male and female being $45 \%$ and $55 \%$ respectively. Likewise, $63 \%$ of the respondents agreed that the improvements were up to their expectations with male and female accounting for $44 \%$ and $56 \%$ respectively.

The perception, views and level of satisfaction of patients regarding dental care received is presented in table 3. Respondents' impressions about dental services at initial visit were recorded as follows; $35 \%$ had quality attention of dentists or dental nurses without undue stress, with $58 \%$ of them being female and $42 \%$ being male. The respondents who reported not to be stressed were $17 \%, 42 \%$ of which were females and males $58 \%$. Majority of the respondents $(38 \%)$ reported that all signs and symptoms will resolve completely after the dental visit with male and female accounting for $35 \%$ and $65 \%$ respectively. Only $7 \%$ of the respondents reported that they will improve but not completely after the dental visit with $80 \%$ being male and $20 \%$ being female. Few (3\%) of the respondents had other reservations about their level of improvement with male and female accounting for $50 \%$ each.

For respondents' opinion regarding the cost of dental treatment in the clinic; few of the patients $(9 \%)$ reported that the cost of dental care is expensive with majority $(64 \%)$ being female and $36 \%$ being male. The cost of dental care was reported to be cheap by $10 \%$ of the respondents with $57 \%$ being male and $43 \%$ being female. Most of the respondents $(81 \%)$ reported that the cost of dental care is affordable with male accounting for $43 \%$ and female $57 \%$.

For the respondents perception of treatment outcome; more than half of the respondents $(52 \%)$ reported good outcome with $43 \%$ and $57 \%$ being male and female respectively. Only 5\% of the respondents stated that the outcome was fair with equal response from both male and female $(50 \%)$. Majority of the respondents $(93 \%)$ were pleased with the dental care received with $46 \%$ being male and $54 \%$ being female while $7 \%$ of the respondents were not pleased with the dental care received with majority being female (70\%) and male being $30 \%$.

For respondents impression about subsequent visit for dental care; majority of the respondents (93\%) are encouraged to visit the dental clinic for future dental care with male and female accounting for $45 \%$ and $55 \%$ respectively. 
Few of the respondents (7\%) are discouraged for further dental visit with male being $40 \%$ and female $60 \%$. Most of the respondents $(95 \%)$ based on their experience will encourage others to visit the clinic for dental care with male and female being $45 \%$ and $55 \%$ respectively. Only $5 \%$ of the respondents will not encourage others to visit the clinic for dental care with male and female accounting for $43 \%$ and $57 \%$ respectively. For respondents subjective opinion about their overall satisfaction; majority of the respondents $(65 \%)$ stated that the dental care was satisfactory, most of which were female (56\%) and male $44 \%$. Lesser percentage $31 \%$ of the patients reported that the dental care received was very satisfactory with male and female accounting for $47 \%$ and $53 \%$ respectively. Only few (4\%) of the respondents reported that the dental care received was not satisfactory with male being $33 \%$ and female $67 \%$.

\section{DISCUSSION}

Patients require regular oral health examinations and dental treatments to ease discomfort, improve dental appearance and functions (1). If a patient is to be adequately served, then he or she must have a voice in the process of care.

Satisfaction from dental treatment is considered to be an important issue that influences the attitude and cooperation of patients. It is associated with the quality of treatment and other variables which could be said to be physical, emotional, social and financial in nature. Several studies $(1,6,8,9)$ have reported that women are more likely to seek dental care than men. This is consistent with this study in which the higher percentage of respondents was females. This is probably because females are more aesthetically concerned and are more health conscious compared to the males.

Previous studies $(10,11)$ have reported that women have greater exposure to dental services and these moderate their expectations and satisfactions hence women are more satisfied than men. The finding of this study is in consonance with the previous reports as female genders were more satisfied than males.

Previous study reported that patients who are single exhibited low overall satisfaction (12). This study showed that larger percentage of respondents $(67.3 \%)$ were singles. This is probably influenced by the location of the study since majority of the population are students.

Contrary to a research(13) which posited that the less educated rather than educated attach a higher priority to care, the majority of the respondents $(78.0 \%)$ in this research were educated and had tertiary education, this is in alignment with some previous studies $(1,14)$. The findings of this research is however probably because the OAUTHC dental clinic in which this study was carried out is within the university setting and hence, gets her patronage from members of the university community which largely are students.

Several scholars (6-8) have reported patients' satisfaction with care to be influenced by the dentists' communicative behavior. Also, desirable interactions have been linked to patients' satisfaction (15)The findings of this research is similar to the previous studies $(6,7,16)$ in that the respondents were satisfied with the dentists communicative behavior and interactions, as majority of the patients stated that they were well carried along in the course of the treatments and their treatment outcome was similar to the information given to them.

Previous study (18) have listed some of the factors which affect the satisfaction level of patients utilizing outpatient services to include unusually long waiting time at registration counter, irritable behavior of registration clerk, lack of proper space for waiting, too long waiting time before consultation, undesirable behavior of doctors and communication gap between doctors and patients. In this study, majority of the respondents stated that the waiting area was comfortable, that they did not wait for too long before consultation and that they were well attended to by the receptionist. This is similar to most reports in the literature $(7,18)$.

Infection control practice is essential especially in handling instruments during treatments to reduce and/or prevent spread of infections hence instruments handling is one of the factors that can contribute to patients' satisfaction. Almost all the respondents in this study claimed that the instruments used for their treatment were well handled. This is similar to the report of previous studies in which respondents felt comfortable with the cautions taken in handling instruments to prevent them from contracting any form of infection $(20,21)$.

Similar to previous studies $(1,22)$ which reported high satisfaction levels with dental care, the majority of the patients in this study reported that they are satisfied with the treatments received at the dental hospital, OAUTHC.

\section{CONCLUSION}

This study highlighted the degree of 
satisfaction obtained from dental services rendered at this facility based on multidimensional factors. Further studies are needed to determine the patients' satisfaction following dental treatments so as to continually improve the quality of care delivered. Care providers should also be encouraged to improve the services given to patients.

\section{REFERENCES}

1. Sowole AA. Patient satisfaction with care provided by a district dental clinic: a thesis submitted in part fulfillment of the degree of MSc (Dent) in the Department of Community Oral Health, University of the Western Cape. 2007.

2. Butters JM, Willis DOA. Comparison of patient satisfaction among current \& former dental school patients. J. Dent. Educ. 2000;64:409-415.

3. Lahti S, Hausen H, Kaarianinen R. Patients' expectations of an ideal dentist and their view concerning the dentist they visited: Does it conform with the expectations and how well they conform. Community Dent Oral Epidemiol. 1996;24:240-244.

4. Newsome PRH, Wright GH. A review of patient satisfaction: Concept of patient satisfaction. British Medical Journal. 1999;186:161-165.

5. Stouthard A, Hartman A, Hoogstraten J. Development of a Dutch Version of the Dental Visit Satisfaction Scale. Community Dent Oral Epidemiol. 1992;20:351-3.

6. Schouten BC, Ejikman MA, Hoogstaten J. Information and participation preferences of dental patients. J. Dent Res. 2004;83:961-5.

7. Okullo I, Ashton A, Haugejorden O. Influence of perceived performance on satisfaction with oral health care among adolescents. Community Dent Oral Epidemiol. 2004;32:447-55.

8. Vered Y, Zadik D, Mersel A. The influence of socio-demographic and psychological variables on the level of satisfaction of geriatric patients from dental care.RefuatHapehVehashinoyin. 2002;19:58-61.

9. Yoshida N, Mataki, S. Influence of patient perception on their acceptance and understanding of dental care within an education system. J. Med. Dent. Sci. 2002;49:143-149.

10. Buthaina A, Al-Mudafa Mohamed AA, MoussabMaha A, Al-TerkyaGhaneema D, Al-
DakhilaAlaa E, El-FarargyaSadad S \& AlOuzairia. Patient Satisfaction with Three Dental Speciality Services: a Centre-Based Study. Med PrincPract. 2003;12:39-43.

11. Reifel NM, Rana H \& Marcus M. Consumer satisfaction. Adv Dent Res. 1997;11:281-290.

12. Kun-Tsung Lee, Chun-Ming Chen, Ju-Hui Wu. Patient satisfaction with the quality of dental treatment provided by interns.Journal of Dental Science. 2013;8(2):177-183.

13. Goedhart H, Eijkman M, ter Horst G. Quality of dental care: the view of regular attenders.CommunityDent.OralEpidemiol. 1996;26:28-31.

14. Gurdal P, Cankaya H, Onem E, Dincer S \&Yilmaz T. Factors of patient satisfaction/dissatisfaction in a dental faculty outpatient clinic in Turkey. Community Dent Oral Epidemiol. 2000;28:4619.

15. Mckeitten EJ. The patient's image of the dentist. J Am College Dent. 1966;33:87-107.

16. Kolslowsky M, Bailit $H$ \&VallUzzo $P$. Satisfaction of the patient and provider: evaluation by questionnaire. J. Public Health Dent. 1974;34:188-194.

17. Fracis V. Gaps in doctor-patient communication: patient's response to medical advice. N Engl J Med. 1969;280:259.

18. Trakroo PL. Reaction of the patients toward the evening OPD.Services in hospital of Delhi, Journal of Hospital Administration. 1977;14:21321

19. Farah S, Tashkandi, Lama O, Hejazi, Hanadi S, \&Lingawi.Patients' Satisfaction with Dental Care Services Provided by Educational Dental Hospital.International Journal of Health Sciences \& Research. 2017;7:135-140.

20. McCarthy GM, Koval JJ \& MacDonald JK. Occupational injuries and exposures among Canadian dentists: The results of a national survey. Infect Control HospEpidemiol. 1999;20:331-336.

21. Boswell S. The patient's perspective. Tex Dent J. 1994;11:30-1.

22. Al-Mudaf BA, Moussa MA, Al-TerkyMA, AlDakhil GD, El-Farargy AE \& Al- Ouzairi SS. Patient satisfaction with three dental speciality services: a centre-based study. Med PrincPract. $2003 ; 12: 39-43$ 
Table 1: Respondents' Demographic Information

\begin{tabular}{|c|c|c|c|}
\hline & & Frequency & Percentage \\
\hline \multirow[t]{4}{*}{ Age (years) } & $<10$ & 1 & 0.7 \\
\hline & $11-30$ & 102 & 68.0 \\
\hline & $31-50$ & 23 & 15.3 \\
\hline & $>71$ & 5 & 3.3 \\
\hline \multirow[t]{2}{*}{ Gender } & Male & 67 & 44.7 \\
\hline & Female & 83 & 55.3 \\
\hline \multirow[t]{2}{*}{ Marital Status } & Single & 101 & 67.3 \\
\hline & Married & 49 & 32.7 \\
\hline \multirow[t]{7}{*}{ Educational background } & No education & 3 & 2.0 \\
\hline & Primary education & 4 & 2.7 \\
\hline & Secondary education & & \\
\hline & Tertiary education & 26 & 17.3 \\
\hline & Students & & \\
\hline & Professionals & 117 & 78.0 \\
\hline & Retirees & & \\
\hline \multirow[t]{5}{*}{ Occupation } & Artisans & 92 & 61.3 \\
\hline & & 36 & 24.0 \\
\hline & & 6 & 4.0 \\
\hline & & 16 & 10.7 \\
\hline & Total & 150 & 100.0 \\
\hline
\end{tabular}


Table 2: Level of patients' satisfaction based on patient's subjective opinion

\begin{tabular}{|c|c|c|c|c|c|c|c|}
\hline Variables & YES & & A & $\mathrm{NO}$ & & $\mathrm{D}$ & $\overline{\mathrm{P}}$ \\
\hline & $\mathrm{M}$ & F & $\%$ & $\mathrm{M}$ & F & $\%$ & value \\
\hline Do you think dental clinic is well & $59(44 \%)$ & $75(56 \%)$ & $134(89 \%)$ & $8(50 \%)$ & $8(50 \%)$ & $16(11 \%)$ & 1.51 \\
\hline \multicolumn{8}{|l|}{ located (to give accessibility) } \\
\hline Is the waiting area comfortable? & $47(42 \%)$ & $66(58 \%)$ & $113(75 \%)$ & $20(54 \%)$ & $17(46 \%)$ & $37(25 \%)$ & 1.53 \\
\hline Did you wait a long time to see the & $18(41 \%)$ & $26(59 \%)$ & $44(29 \%)$ & $49(46 \%)$ & $57(54 \%)$ & $106(71 \%)$ & 1.51 \\
\hline \multicolumn{8}{|l|}{ dentist? } \\
\hline Do you think there are enough & $63(45 \%)$ & $77(55 \%)$ & $140(93 \%)$ & $3(30 \%)$ & $7(70 \%)$ & $10(7 \%)$ & 1.51 \\
\hline \multicolumn{8}{|l|}{ personnel here to give dental care? } \\
\hline Are there enough dental operative here? & $59(43 \%)$ & $79(57 \%)$ & $138(92 \%)$ & $8(67 \%)$ & $4(33 \%)$ & $12(8 \%)$ & 1.54 \\
\hline Were you well attended to by the & $45(41 \%)$ & $65(59 \%)$ & $110(73 \%)$ & $9(50 \%)$ & $9(50 \%)$ & $40(27 \%)$ & 1.55 \\
\hline \multicolumn{8}{|l|}{ receptionist? } \\
\hline Do you have any understanding about & $45(47 \%)$ & $50(53 \%)$ & $95(63 \%)$ & $22(40 \%)$ & $33(60 \%)$ & $55(37 \%)$ & 1.52 \\
\hline \multicolumn{8}{|l|}{ what is causing your complaints before } \\
\hline \multicolumn{8}{|l|}{ commencement of the treatment based } \\
\hline \multicolumn{8}{|l|}{ on the explanations? } \\
\hline Do you know how long the treatment & $24(49 \%)$ & $25(51 \%)$ & $49(33 \%)$ & $43(43 \%)$ & $58(57 \%)$ & $101(67 \%)$ & 1.52 \\
\hline \multicolumn{8}{|l|}{ will take? } \\
\hline Do you think you were delayed in the & $18(41 \%)$ & $26(59 \%)$ & $44(29 \%)$ & $49(46 \%)$ & $57(54 \%)$ & $106(71 \%)$ & 1.51 \\
\hline \multicolumn{8}{|l|}{ course of the treatment? } \\
\hline Do you think the instruments used for & $63(44 \%)$ & $80(56 \%)$ & $143(95 \%)$ & $4(57 \%)$ & $3(43 \%)$ & $7(5 \%)$ & 1.52 \\
\hline \multicolumn{8}{|l|}{ your treatment were well handled? } \\
\hline Were you carried along during the & $62(45 \%)$ & $75(55 \%)$ & $137(91 \%)$ & $5(38 \%)$ & $8(62 \%)$ & $13(9 \%)$ & 1.51 \\
\hline \multicolumn{8}{|l|}{ treatment? } \\
\hline Did you experience anything strange & $6(40 \%)$ & $9(60 \%)$ & $15(10 \%)$ & $74(55 \%)$ & $61(45 \%)$ & $135(90 \%)$ & 1.53 \\
\hline \multicolumn{8}{|l|}{ aside what you were told before the } \\
\hline \multicolumn{8}{|l|}{ treatment? } \\
\hline Are there instructions you were told to & $63(45 \%)$ & $78(55 \%)$ & $141(94 \%)$ & $4(44 \%)$ & $5(56 \%)$ & $9(6 \%)$ & 1.51 \\
\hline \multicolumn{8}{|l|}{ follow after the treatment? } \\
\hline Did you understand the instruction? & $64(45 \%)$ & $79(55 \%)$ & $143(95 \%)$ & $3(43 \%)$ & $4(57 \%)$ & $7(5 \%)$ & 1.53 \\
\hline Were you told to come back for check- & $55(48 \%)$ & $59(52 \%)$ & $114(76 \%)$ & $12(33 \%)$ & $24(67 \%)$ & $36(24 \%)$ & 1.54 \\
\hline \multicolumn{8}{|l|}{ up? } \\
\hline Were you told the expectation of the & $41(49 \%)$ & $43(51 \%)$ & $84(56 \%)$ & $26(39 \%)$ & $40(61 \%)$ & $66(44 \%)$ & 1.52 \\
\hline
\end{tabular}


Table 3: Patient's perception and level of satisfaction of dental care received

\begin{tabular}{lllll}
\hline Variables & $N$ & Female & $\%$ & P value \\
& Male & & \\
\hline What was your impression about services in this & & & \\
clinic before you visit? & & & \\
I feel I will be attended to without undue stress & $22(42 \%)$ & $31(58 \%)$ & $53(35 \%)$ & \\
I feel I will be stressed before receiving attention & $15(58 \%)$ & $11(42 \%)$ & $26(17 \%)$ \\
I feel my complaints will be perfectly treated after & $20(35 \%)$ & $37(65 \%)$ & $57(38 \%)$ & \\
the visit & & & \\
I feel my complaints will be treated to certain extent & $8(80 \%)$ & $2(20 \%)$ & $10(7 \%)$ \\
Others & $2(50 \%)$ & $2(50 \%)$ & $4(3 \%)$ \\
What is your opinion about the cost of treatment & & & \\
in this clinic & & & \\
Expensive & $5(36 \%)$ & $9(64 \%)$ & $14(9 \%)$ & 1.52 \\
Affordable & $53(43 \%)$ & $69(57 \%)$ & $122(81 \%)$ \\
Cheap & $6(43 \%)$ & $14(10 \%)$ \\
\hline
\end{tabular}

